\title{
Irritable Bowel Syndrome and Dietary Habits in Northern Saudi Arabia
}

\author{
Saleh Hadi Alharbi', Fahad A. Alateeq1', Khalil Ibrahim Alshammari', \\ Abdulaziz Saad Sharea Alshammri², Naif Abdulmohsen Naif Alabdali², \\ Motab Ali Saud Alsulaiman², Sami Mamdouh Ibrahim Algothi', \\ Abdulrahman Sulaiman Altoraifi' ${ }^{2}$, Maha Qasem Almutairi' ${ }^{2}$, Hussain Gadelkarim Ahmed ${ }^{2,3}$ \\ ${ }^{1}$ Faculty of Medicine, Al-Imam Mohammad Ibn Saud Islamic University, Riyadh, KSA \\ ${ }^{2}$ College of Medicine, University of Hail, Hail, KSA \\ ${ }^{3}$ Department of Histopathology and Cytology, FMLS, University of Khartoum, Khartoum, Sudan \\ Email: hussaingad5@gmail.com
}

How to cite this paper: Alharbi, S.H., Alateeq, F.A., Alshammari, K.I., Alshammri, A.S.S., Alabdali, N.A.N., Alsulaiman, M.A.S., Algothi, S.M.I., Altoraifi, A.S., Almutairi, M.Q. and Ahmed, H.G. (2019) Irritable Bowel Syndrome and Dietary Habits in Northern Saudi Arabia. Health, 11, 289-297.

https://doi.org/10.4236/health.2019.113025

Received: February 13, 2019

Accepted: March 2, 2019

Published: March 5, 2019

Copyright $\odot 2019$ by author(s) and Scientific Research Publishing Inc. This work is licensed under the Creative Commons Attribution International License (CC BY 4.0).

http://creativecommons.org/licenses/by/4.0/

\begin{abstract}
Background: dietary habit is one of the most universally recounted initiators of irritable bowel syndrome (IBS). The objective of the present study was to determine the role of some dietary habits in the etiology of IBS in Northern Saudi Arabia. Methodology: In this community based cross-sectional survey, data about IBS were obtained from 930 Saudi volunteers living in the city of Hail, Northern Saudi Arabia. IBS was diagnosed using Rome IV criteria. Results: The prevalence of IBS was $11 \%$ among males vs. $12.5 \%$ among females. The prevalence of IBS symptoms among males was $30 \%$ vs. $36.5 \%$ females. IBS was significantly associated with reduced water intake, the RR $(95 \% \mathrm{CI})=$ 1.1800 (1.0146 to 1.3722 ), $\mathrm{P}=0.0316$. In the present study, the majority of the study population 904/929 (97.3\%) didn't accustom to vegetables/fruits intake. Conclusion: IBS is prevalent in Northern Saudi Arabia, both among males and females with relatively increasing among females. Low water intake and insufficient fibers intake (particularly, in vegetables and fruits) might be behind the growing prevalence of IBS in Saudi Arabia.
\end{abstract}

\section{Keywords}

Irritable Bowel Syndrome, Dietary Habits, Saudi Arabia

\section{Introduction}

Irritable bowel syndrome (IBS) is a chronic bowel disorder, which considerably disturbs the quality of life and works productivity. The prevalence rates of IBS are ranging from $7 \%$ to $21 \%$ in the general population [1]. IBS is branded by 
troubles in bowel habits and abdominal pain in the absence of recognized organic pathology [2]. IBS is widely accepted as a mysterious brain-gut complaint [3]. The pathophysiology is today planned nearby a consensual hypothesis called the "brain-gut axis", which collects all the stimuli of peripheral factors as gut microbiota or local serotonin secretion, on the central pain perception, contributing to visceral hypersensitivity and transit modifications [4]. IBS Patients usually experience abdominal pain and altered bowel habit, with either predominantly diarrhea (IBS-D), constipation (IBS-C), or both (IBS-M) [5]. Stress and concomitant psychopathologies such as somatization, anxiety, and depression are thought to play a significant role in the development, clinical course and response to treatment [6].

The diagnosis is made according to a symptom-based classification system, the Rome Criteria, with the latest version, Rome IV, recently released. Rome IV has been a compendium of the knowledge accumulated since Rome III was published [7].

It was well established that some diets, especially onions, garlic, and coffee, were reported to increase the IBS symptoms. Decreasing carbohydrate diets and increasing fiber diet would enhance the patient health where the symptoms were been reduced [8]. Novel approaches to treatment include lifestyle modification, changes in diet, probiotics, and pharmacotherapy directed to the motility, sensation, and intraluminal milieu of patients with IBS [9].

In Saudi Arabia, the prevalence of IBS was $14.4 \%$. Food hypersensitivity, morbid anxiety, and family history were the predictors of IBS [10]. Therefore, the present study aimed to determine the role of some dietary habits in the etiology of IBS in Northern Saudi Arabia.

\section{Materials and Methods}

In this community based cross-sectional survey, data about IBS were obtained from 930 Saudi volunteers living in the city of Hail, Northern Saudi Arabia, during the period from October 2018 to February 2019. Participants were randomly selected by simple random regardless of age, gender, and education or occupation.

A Purposeful questionnaire was designed and used for obtaining the necessary data. A medical student filled each questionnaire during the interview. The following information was obtained from each participant: age, sex, and education level, and some dietary habits (intake of fruits/vegetables, and frequency of daily water intake). IBS was diagnosed based on Rome IV Criteria. Recurrent abdominal pain, on average, at least one day/week in the last three months, associated with two or more of the following criteria: Related to defecation; Associated with a change in frequency of stool; Associated with a change in form (appearance) of stool. Criteria fulfilled for the last three months with symptom onset at least six months before diagnosis. Those didn't completely fulfillment Rome IV criteria were categorized as patients with IBS symptoms (intermittent IBS symptoms).

\subsection{Data Analysis}

Statistical Package for Social Sciences (version 16) was used for analysis and to 
perform a Pearson Chi-square test for statistical significance (P value). The 95\% confidence level and confidence intervals were used. A P value less than 0.05 was considered statistically significant.

\subsection{Ethical Consent}

Each participant was asked to sign a written ethical consent during the questionnaire's interview. The informed ethical consent form was designed and approved by the ethical committee of the College of Medicine (University of Hail, Saudi Arabia) Research Board.

\section{Results}

The present study, involved 930 Saudi volunteers, their ages ranging from 18 to 78 years with a mean age of 33 years. Out of 930 participants, 395/930 (42\%) were males and 535/930 (58\%) females, giving males' females' ration of 1.00:1.35. The majority of the study subjects were found at age range $21-29$ years followed by $\geq 50$ years, representing 360/930 (39\%) and 157/930 (17\%), correspondingly, as indicated in Table 1.

The prevalence of IBS was $11 \%$ among males vs. $12.5 \%$ among females. The prevalence of IBS symptoms among males was $30 \%$ vs. $36.5 \%$ females. The prevalence rates of IBS and IBS symptoms in the age group $\leq 20$ years were $12.4 \%$ and $36.4 \%$, respectively. The prevalence rates of IBS and IBS symptoms in the age group $21-29$ years were $10.7 \%$ and $34.3 \%$, respectively. The prevalence rates of IBS and IBS symptoms in the age group $30-39$ years were $14.5 \%$ and $42 \%$, respectively. The prevalence rates of IBS and IBS symptoms in the age group 40 49 years were $13.2 \%$ and $27.2 \%$, respectively. The prevalence rates of IBS and IBS symptoms in the age group $\geq 50$ years were $10.4 \%$ and $30 \%$, respectively, as indicated in Table 2 and Figure 1.

Table 3 summarizes the relationship between IBS status and food habits. Out of 132 persons, use to consume $<0.5$ liters/day of water 19/132 (14.4\%) and $44 / 132$ (33.3\%) were found with IBS and intermittent IBS symptoms. Out of 247 participants use to consume 0.5 - 1.00 liters of water 29/247 (11.7\%), and 85/247 (34.4\%) were found with IBS and intermittent IBS symptoms. IBS was significantly associated with reduced water intake, the RR $(95 \% \mathrm{CI})=1.1800$ (1.0146 to 1.3722), $\mathrm{P}=0.0316$, as shown in Figure 2. In the present study, the majority of the study population 904/929 (97.3\%), didn't accustom to vegetables/fruits intake. On the other hand, the majority of the study subjects were found accustomed to caffeine $784 / 917$ (85.5\%) intake. Out of 133 persons, who didn't use caffeine, 19/133 (57.6\%) and 47/133 (35.3\%) were found with IBS and intermittent IBS, respectively. Use of caffeine was not found to be a significant factor for IBS, the RR $(95 \%$ CI $)=0.8996$ ( 0.7453 to 1.0858$), P=0.2705$, as shown in Figure 2. Moreover, home food, fast food, and spicy food didn't show statistically significant association with IBS, though there were increased proportions of patients among individuals with these habits, as indicated in Table 3 and Figure 2. 
Table 1. Distribution of the study population by age and gender.

\begin{tabular}{cccc}
\hline Age Group & Males & Females & Total \\
\hline$\leq 20$ years & 13 & 108 & 121 \\
$21-29$ & 92 & 268 & 360 \\
$30-39$ & 78 & 63 & 141 \\
$40-49$ & 97 & 54 & 151 \\
$\geq 50$ & 115 & 42 & 157 \\
Total & 395 & 535 & 930 \\
\hline
\end{tabular}

Table 2. IBS status by gender and age.

\begin{tabular}{ccccc}
\hline Variable & IBS (Rome VI) & IBS Symptoms & No IBS & Total \\
\hline Gender & & & & \\
\hline Males & 43 & 118 & 230 & 391 \\
Females & 66 & 193 & 270 & 529 \\
Total & 109 & 311 & 500 & 920 \\
\hline Age & & & & \\
$\leq 20$ years & 15 & 44 & 62 & 121 \\
$21-29$ & 38 & 122 & 196 & 356 \\
$30-39$ & 20 & 58 & 60 & 138 \\
$40-49$ & 20 & 41 & 90 & 151 \\
$\geq 50$ & 16 & 46 & 92 & 154 \\
Total & 109 & 311 & 500 & 920 \\
\hline
\end{tabular}

Table 3. IBS status by dietary habits.

\begin{tabular}{|c|c|c|c|c|c|}
\hline Category & Variable & IBS & Intermittent IBS & No IBS & Total \\
\hline \multicolumn{6}{|l|}{ Water Intake } \\
\hline & $<0.5$ liters/day & 19 & 44 & 69 & 132 \\
\hline & 0.5 - 1.00 liters & 29 & 85 & 133 & 247 \\
\hline & $1.00-2.00$ liters & 41 & 105 & 190 & 336 \\
\hline & $>2.00$ liters & 18 & 70 & 97 & 185 \\
\hline & Total & 107 & 304 & 489 & 900 \\
\hline \multicolumn{6}{|c|}{ Vegetables/Fruits } \\
\hline & Yes & 3 & 7 & 15 & 25 \\
\hline & No & 107 & 307 & 490 & 904 \\
\hline & Total & 110 & 314 & 505 & 929 \\
\hline \multicolumn{6}{|l|}{ Caffeine } \\
\hline & Yes & 89 & 261 & 434 & 784 \\
\hline & No & 19 & 47 & 67 & 133 \\
\hline & Total & 108 & 308 & 501 & 917 \\
\hline
\end{tabular}




\section{Continued}

\begin{tabular}{cccccc}
\hline Home food & & & & & \\
\hline & Yes & 48 & 166 & 215 & 429 \\
& No & 62 & 148 & 290 & 500 \\
& Total & 110 & 314 & 505 & 929 \\
\hline Fast food & & 23 & 66 & 143 & 232 \\
\hline Yes & 87 & 248 & 362 & 697 \\
& No & 110 & 314 & 505 & 929 \\
\hline & Total & & & & \\
\hline & Yes & 36 & 75 & 132 & 243 \\
& No & 74 & 239 & 373 & 686 \\
& Total & 110 & 314 & 505 & 929 \\
\hline
\end{tabular}

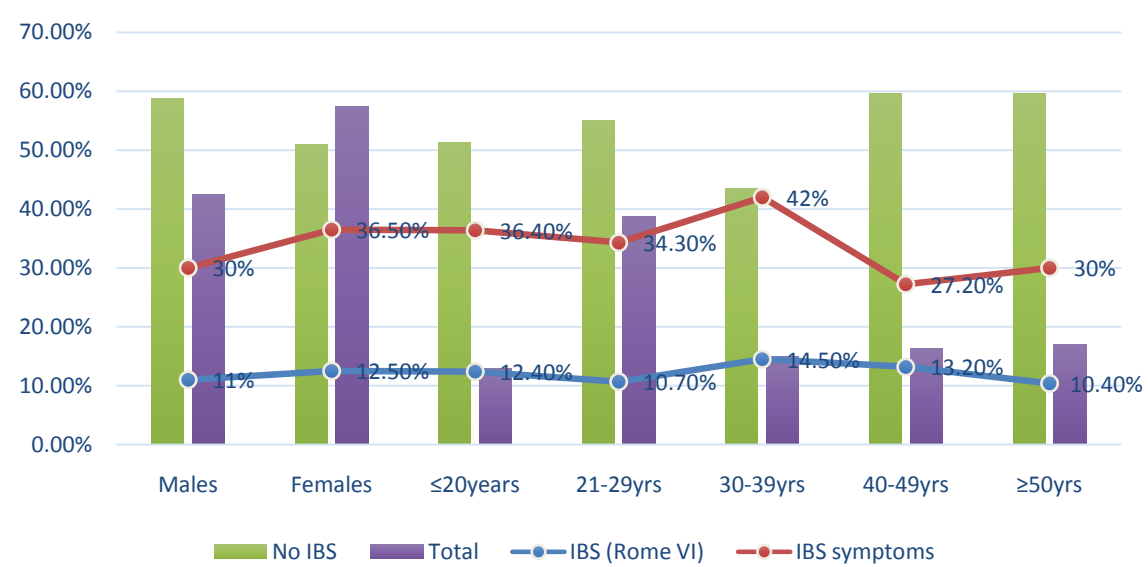

Figure 1. The prevalence rates of IBS by gender and age.

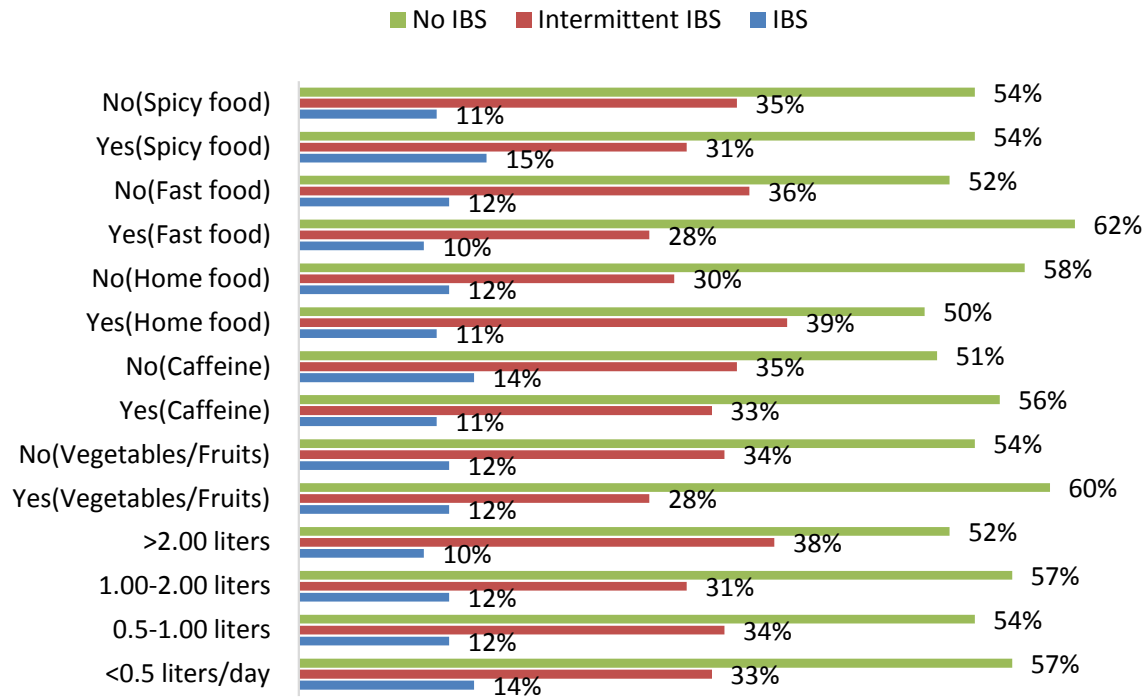

Figure 2. IBS status by food habits. 


\section{Discussion}

The assessment of factors that contributes to the etiology of IBS is very important for all communities. Food is one of the most commonly reported triggers of irritable bowel syndrome (IBS) symptoms. However, the role of diet in the etiology and management of IBS has not been clearly established [10]. Thus this study was aiming at determining the role of some dietary as a contribution to the burden of IBS in Northern Saudi Arabia.

In the present study, the prevalence of IBS was $11 \%$ among males vs. $12.5 \%$ among females. The prevalence of IBS symptoms among males was 30\% vs. $36.5 \%$ females. As Rome IV criteria were employed in this study, several cases were excluded, though they have IBS symptoms. Such cases were put in a group of IBS symptoms. These prevalence rates were relatively similar to previously reported figures, although almost all previous studies were reporting epidemiology of IBS using Rome II or Rome III criteria. Such points may predict the increasing of IBS prevalence among the Northern Saudi population. The study by Ibrahim et al. [11] from Western Saudi Arabia, reported An IBS prevalence of $14.4 \%$ among nurses. Another study from Saudi Arabia has reported a prevalence of $21 \%$ among medical students and higher among females than males but were highest among fifth-year students for both genders [12].

In the present study, the highest prevalence rate was identified in the age group 30 - 39 followed by 40 - 49 years, representing $41.5 \%$ and $13.2 \%$, respectively. Although the studies from Saudi Arabia didn't correlate the relationship between IBS and age in different age groups, the published literature established the signifying of IBS in the age range 30 - 40 years [13].

About dietary habits, IBS was significantly associated with reduced water intake, the RR $(95 \% \mathrm{CI})=1.1800$ (1.0146 to 1.3722$), \mathrm{P}=0.0316$. Daily fiber intake of $25 \mathrm{~g}$ can increase stool frequency in patients with chronic functional constipation, and this effect can be significantly enhanced by increasing fluid intake to 1.5 - 2.0 liters/day [14]. Fluid loss and fluid restriction and thus dehydration increase constipation. It is therefore essential to maintain hydration as the prevention of constipation [15]. Mineral water supplementation treatment for functional dyspepsia or constipation accompanying IBS can improve gastric acid output and intestinal transit time [16]. However, it was found that cold water intake leads to lowered visceral perception thresholds in IBS patients that were inversely relevant to the abdominal symptoms in symptomatic diarrhea-predominant IBS patients. The alteration of rectal sensitivity and abdominal symptoms following cold water stimulation provided further objective evidence for visceral hypersensitivity in IBS patients [17].

Although the use of caffeine was not found to be a significant factor for IBS, there was a slightly increased risk in the current study. Caffeine, one of the world's most popular psychoactive substances, is sought for its central nervous system stimulant effects. If coffee, tea, and soda alone do not provide the desired stimulation, some consumers are turning to the newest fad in the caffeine mar- 
ket, energy drinks [18]. Caffeine stimulates gastric acid secretion and colonic motor activity, mainly coffee [19]. The National Institute for Health and Care Excellence (NICE) guidelines suggest limiting the consumption of coffee and tea to no more than 3 cups per day [20].

The present study showed that about $97.3 \%$ of the participants didn't consume vegetables/fruits regularly. It is well known that eating a variety of vegetables every day is associated with favorable health across the life course. Internationally, food-based dietary guidelines encourage the consumption of a variety of vegetables and fruit but globally, people are not eating enough vegetables to meet the three-or-more-a-day guideline. Vegetables are good sources of vitamins and minerals, fiber, and many bioactive compounds that promote health and provide energy [21].

Moreover, home food, fast food, and spicy food didn't show statistically significant association with IBS, though there were increased proportions of patients among individuals with these habits. Food is one of the most commonly reported triggers of IBS symptoms. Some diets, especially onions, garlic, and coffee, were reported to increase the IBS symptoms [8]. However, in most instances, one's can't control the food intake except when it is homemade. Consumption of spicy foods is directly associated with IBS, particularly in women [22]. Intra-meal fluid intake, chewing insufficiency, higher tooth loss, and the consumption of spicy and fried food were associated with an increased risk of IBS [23].

The limitations of the present study include its cross sectional setting and its community based design.

\section{Conclusion}

IBS is prevalent in Northern Saudi Arabia, both among males and females with relatively increasing among females. Low water intake and insufficient fibers intake (particularly, in vegetables and fruits) might be behind the growing prevalence of IBS in Saudi Arabia.

\section{Acknowledgements}

Authors would like to thank medical students at the College of Medicine, University of Hail, for their active contribution in the collection of data, including Fadyah Mohammed Alradaddi, Nuseibah Saleh Almakhalfi, Rasha Saidan Alshammari, Ethar Abed Alsulami, Raghad Abdullah Almeshari, Ahlam Aedh Naqa Asuhaymi, Maram Abdulaziz Alhejail.

\section{Conflicts of Interest}

The authors declare no conflicts of interest regarding the publication of this paper.

\section{References}

[1] Chey, W.D., Kurlander, J. and Eswaran, S. (2015) Irritable Bowel Syndrome: A 
Clinical Review. JAMA, 313, 949-958. https://doi.org/10.1001/jama.2015.0954

[2] Weaver, K.R., Melkus, G.D. and Henderson, W.A. (2017) Irritable Bowel Syndrome. American Journal of Nursin, 117, 48-55. https://doi.org/10.1097/01.NAJ.0000520253.57459.01

[3] Grenham, S., Clarke, G., Cryan, J.F. and Dinan, T.G. (2011) Brain-Gut-Microbe Communication in Health and Disease. Frontiers in Physiology, 2, 94. https://doi.org/10.3389/fphys.2011.00094

[4] Holtmann, G.J., Ford, A.C. and Talley, N.J. (2016) Pathophysiology of Irritable Bowel Syndrome. The Lancet Gastroenterology \& Hepatology, 1, 133-146. https://doi.org/10.1016/S2468-1253(16)30023-1

[5] Canavan, C., West, J. and Card, T. (2014) The Epidemiology of Irritable Bowel Syndrome. Clinical Epidemiology, 6, 71-80. https://doi.org/10.2147/CLEP.S40245

[6] Dekel, R., Drossman, D.A. and Sperber, A.D. (2013) The Use of Psychotropic Drugs in Irritable Bowel Syndrome. Expert Opinion on Investigational Drugs, 22, 329-339. https://doi.org/10.1517/13543784.2013.761205

[7] Drossman, D.A. (2016) Functional Gastrointestinal Disorders: History, Pathophysiology, Clinical Features, and Rome IV. Gastroenterology. https://doi.org/10.1053/j.gastro.2016.02.032

[8] Bardisi, B.M., Halawani, A.K.H., Halawani, H.K.H., et al. (2018) Efficiency of Diet Change in Irritable Bowel Syndrome. Journal of Family Medicine and Primary Care, 7, 946-951.

[9] Camilleri, M. (2018) Management Options for Irritable Bowel Syndrome. Mayo Clinic Proceedings, 93, 1858-1872. https://doi.org/10.1016/j.mayocp.2018.04.032

[10] Ibrahim, N.K., Al-Bloushy, R.I., Sait, S.H., Al-Azhary, H.W., Al-Bar, N.H. and Mirdad, G.A. (2016) Irritable Bowel Syndrome among Nurses Working in King Abdulaziz University Hospital, Jeddah, Saudi Arabia. Libyan Journal of Medicine, 11, Article ID: 30866. https://doi.org/10.3402/ljm.v11.30866

[11] Hayes, P., Corish, C., O’Mahony, E. and Quigley, E.M.M. (2014) A Dietary Survey of Patients with Irritable Bowel Syndrome. Journal of Human Nutrition and Diabetics, 27, 36-47.

[12] Alaqeel, M.K., Alowaimer, N.A., Alonezan, A.F., Almegbel, N.Y. and Alaujan, F.Y. (2017) Prevalence of Irritable Bowel Syndrome and its Association with Anxiety among Medical Students at King Saud bin Abdulaziz University for Health Sciences in Riyadh. Pakistan Journal of Medical Sciences, 33, 33-36. https://doi.org/10.12669/pjms.331.12572

[13] Lovell, R.M. and Ford, A.C. (2012) Global Prevalence of and Risk Factors for Irritable Bowel Syndrome: A Meta-Analysis. Clinical Gastroenterology and Hepatology, 10, 712-721. https://doi.org/10.1016/j.cgh.2012.02.029

[14] Anti, M., Pignataro, G., Armuzzi, A., Valenti, A., Iascone, E., Marmo, R., et al. (1998) Water Supplementation Enhances the Effect of High-Fiber Diet on Stool Frequency and Laxative Consumption in Adult Patients with Functional Constipation. Hepatogastroenterology, 45, 727-732.

[15] Arnaud, M.J. (2003) Mild Dehydration: A Risk Factor of Constipation? European Journal of Clinical Nutrition, 57, S88-S95. https://doi.org/10.1038/sj.ejcn.1601907

[16] Gasbarrini, G., Candelli, M., Graziosetto, R.G., Coccheri, S., Di Iorio, F. and Nappi, G. (2006) Evaluation of Thermal Water in Patients with Functional Dyspepsia and Irritable Bowel Syndrome Accompanying Constipation. World Journal of Gastroenterology, 12, 2556-2562. https://doi.org/10.3748/wjg.v12.i16.2556 
[17] Zuo, X.L., Li, Y.Q., Shi, L., Lv, G.P., Kuang, R.G., Lu, X.F., Li, J.M. and Desmond, P.V. (2006) Visceral Hypersensitivity Following Cold Water Intake in Subjects with Irritable Bowel Syndrome. Journal of Gastroenterology, 41, 311-317. https://doi.org/10.1007/s00535-005-1766-x

[18] Pohler, H. (2010) Caffeine Intoxication and Addiction. The Journal for Nurse Practitioners, 6, 49-42. https://doi.org/10.1016/j.nurpra.2009.08.019

[19] Eswaran, S., Tack, J. and Chey, W.D. (2011) Food: The forgotten Factor in the Irritable Bowel Syndrome. Gastroenterology Clinics of North America, 40, 141-162. https://doi.org/10.1016/j.gtc.2010.12.012

[20] National Institute for Health and Care Excellence (2015) Irritable Bowel Syndrome in Adults: Diagnosis and Management of Irritable Bowel Syndrome in Primary Care. (NICE Clinical Guideline 61) (Updated February 2015. Accessed September 30, 2015). National Institute for Health and Care Excellence, London.

[21] Rush, E., Savile, F., Jalili-Moghaddam, S. and Amoah, I. (2019) Vegetables: New Zealand Children Are Not Eating Enough. Frontiers in Nutrition, 8, 134.

https://doi.org/10.3389/fnut.2018.00134

[22] Esmaillzadeh, A., Keshteli, A.H., Hajishafiee, M., Feizi, A., Feinle-Bisset, C. and Adibi, P. (2013) Consumption of Spicy Foods and the Prevalence of Irritable Bowel Syndrome. World Journal of Gastrointestinal, 19, 6465-1671. ttps://doi.org/10.3748/wjg.v19.i38.6465

[23] Khayyatzadeh, S.S., Kazemi-Bajestani, S.M.R., Mir Mousavi, S.J., Heshmati, M., Khoshmohabbat, S., Ferns, G.A. and Ghayour-Mobarhan, M. (2018) Dietary Behaviors in Relation to Prevalence of Irritable Bowel Syndrome in Adolescent Girls. Journal of Gastroenterology and Hepatology, 33, 4-410. https://doi.org/10.1111/jgh.13908 